\title{
An Assessment on Financial Performance of Listed Companies in the Industry of the New Energy Automobiles in China
}

\author{
Fei Yi \\ School of Management \\ Wuhan University of Technology \\ Wuhan, P.R.China \\ 2252629906@qq.com
}

\begin{abstract}
The thesis in hand analyzes, from a financial perspective, the overall status of global new energy automobiles industry with a special focus on issues emerging in china domestic companies. It chooses 10 financial indicators as research variables and it applies the method of factor analysis. It is an empirical study which has built analytical models and regressive equations for financial assessment within the industry. It finds the financial performance of those listed companies is optimistic in general, but their development process is imbalanced and unstable. It suggests that the companies have to pursue a balanced development, improve their financial management system, and make full use of government policies so as to have a better financial performance. At the same time, the government had better continue to allocate more resources to the industry.
\end{abstract}

Keywords-new energy automobile; factor analysis; financial performance assessment; financial management

\section{INTRODUCTION}

Under a circumstance of increasingly severe energy crisis and environmental pollution, it seems inevitable for all countries to develop low-carbon economy and encourage energy saving and emission reduction. For the automobile industry, it is a very critical moment - developing new energy cars will not only have numerous benefits in environment protection, energy security, and expansion of domestic demand, but also boost the industry to leap forward and change the way of economy growth, thus increasing the competence of whole industry. In western countries, environmental issues have been always treated seriously, so new energy cars play an important role in the development of the automobile industry. Some of the countries support the industry with favorable policies, inputting considerable capital and human resources that help make breakthroughs.[1] In China, recent years have seen a thriving trend in the new energy automobile industry. Its rise is also a beneficial supplement to the comprehensive and sustainable development of China economy. Similar to western countries, much resources and many favorable policies are allocated to the industry in China. Meanwhile, domestic new energy automobile companies have been adapting themselves to the government policies of innovation in science and technology, environment protection, and sustainable development; and they continue to grow by taking the opportunity and advantageous situation. [2] This study is to analyze the existing problems in the listed companies in new energy automobile industry in China. It also gives possible solutions from company perspective and government perspective.

\section{CONSTRUCTION OF INDEX SYSTEM}

On the basis of "Enterprise Performance Assessment System" (by Ministry of Finance) and "Interim Measures on Comprehensive Performance Assessment of state-owned Enterprises"(by State Council), the study in hand has set up an assessment system including ten financial indicators, which can be divided into three categories: operating ability, solvency, and profitability. In specific, indicators of operating ability include: receivables turnover, inventory turnover, current assets turnover, and total assets turnover; the solvency category measures: current ratio, cash ratio, asset-liability ratio, and equity ratio; while profitability is measured by rate of return on total assets and net profit margin. [3] (see Table I)

TABLE I. INDEX SYSTEM

\begin{tabular}{|c|c|c|}
\hline Primary Index & Secondary Index & Computational formula \\
\hline \multirow{4}{*}{ Operating ability } & Receivables turnover & The average balance of operating income / accounts receivable \\
& Inventory turnover & Operating cost/average inventory balance \\
& Current assets turnover & Operating income / average balance of current assets \\
& Total assets turnover & Average operating income / total assets balance \\
\hline \multirow{3}{*}{ Solvency } & Current ratio & Current assets/current liabilities \\
& Cash ratio & Monetary funds/current liabilities \\
& Asset-liability ratio & Total liabilities/total assets \\
& Equity ratio & Total liabilities/total equity of shareholders \\
\hline
\end{tabular}




\begin{tabular}{|c|c|c|}
\hline \multicolumn{2}{|c|}{ Cont. to TABLE I } \\
\hline Profitability & $\begin{array}{c}\text { Rate of return on total assets } \\
\text { Net profit margin }\end{array}$ & $\begin{array}{c}\text { Total net profit / average assets } \\
\text { Net profit / operating income }\end{array}$ \\
\hline
\end{tabular}

\section{DATA COLLECTION AND RESEARCH METHODOLOGY}

In this study, 21 new energy automobile companies listed in Shanghai Stock Exchange or Shenzhen Stock Exchange are chosen to build a factor analysis model; financial data is cited or derived from their annual reports from 2015 to 2018, which are recorded in China Stock Market \& Accounting Research (CSMAR) Database. Three kinds of data are excluded for the following reasons:

1) Companies with their stocks labeled as "special treatment(ST)" or "particular transfer(PT)". Data of such companies are excluded because they have had deficit for 3 years in a row, or other abnormal financial problems. Such data will affect the accuracy of this study;

2) Companies that are listed in stock markets less than two years. It is likely for these companies to technically beautify their performance in a short period, so as to go public successfully. Such data might be biased;

3) Companies that have abnormal information change or delisted companies. Data of such companies is excluded for its special feature.

As described earlier, ten financial indicators are cited or deprived from recorded data, i.e. receivables turnover, inventory turnover, current assets turnover, total assets turnover, current ratio, cash ratio, asset-liability ratio, equity ratio, return on total assets, and net profit margin. [4] The research method is using Excel as tool for primary data processing and SPSS for factor analysis.

\section{RESULTS OF FACTOR ANALYSIS}

\section{A. KMO \& Bartlett test}

The tool, SPSS, is applied here to standardize 10 financial indicators of each sample company. After processing 210 groups of data, the results of their correlation test are shown in Table II.

TABLE II. KMO AND BARTLETT'S TEST

\begin{tabular}{|c|c|c|}
\hline & $\begin{array}{c}\text { Kaiser-Meyer-Olkin Measure of } \\
\text { Sampling Adequacy. }\end{array}$ & .469 \\
\hline Bartlett's Test of & Approx. Chi-Square & 73.508 \\
Sphericity & df & 28 \\
Sig. & .000 \\
\hline
\end{tabular}

KMO and Bartlett tests are used to preliminarily determine whether the quoted data is suitable for factor analysis. The statistics of Bartlett test are based on the determinant of the correlation coefficient matrix. If the value is large, then the zero-hypothesis should be rejected. Instead, It should be considered that the correlation coefficient matrix is not a unit matrix, that is, the correlation between the original variables is suitable for factor analysis. [5] The value of Sig in Table II is much less than 0.05, which is acceptable for factor analysis.

\section{B. Extracting the common factors}

TABLE III. TOTAL VARIANCE EXPLAINED

\begin{tabular}{|c|c|c|c|c|c|c|c|c|c|}
\hline \multicolumn{4}{|c|}{ Initial Eigenvalues } & \multicolumn{3}{|c|}{ Extraction Sums of Squared Loadings } & \multicolumn{3}{|c|}{ Rotation Sums of Squared Loadings } \\
\hline$C$ & $T$ & $\%$ of $V$ & Cum\% & $T$ & \& of $V$ & Cum\% & $T$ & $\%$ of $V$ & Сum\% \\
\hline 1 & 3.1 & 31.38 & 31.38 & 3.13 & 31.4 & 31.4 & 3.01 & 30.13 & 30.13 \\
\hline 2 & 2.6 & 26.09 & 57.47 & 2.61 & 26.1 & 57.5 & 2.37 & 23.71 & 53.84 \\
\hline 3 & 1.4 & 14.90 & 72.38 & 1.49 & 14.9 & 72.4 & 1.85 & 18.5 & 72.38 \\
\hline 4 & .88 & 8.887 & 81.26 & & & & & & \\
\hline 5 & .73 & 7.306 & 88.57 & & & & & & \\
\hline 6 & .53 & 5.377 & 93.95 & & & & & & \\
\hline 7 & .37 & 3.696 & 97.64 & & & & & & \\
\hline 8 & 13 & 1.374 & 99.02 & & & & & & \\
\hline 9 & .08 & .858 & 99.88 & & & & & & \\
\hline 0 & .01 & 120 & 100.0 & & & & & & \\
\hline
\end{tabular}

As factor analysis is used here, three principal components in Table III with characteristic roots greater than 1 are extracted. The variance contribution rate of the first principal component is $31.38 \%$; the second, $26.09 \%$; and the third, $14.90 \%$. The subtotal of the three components is $72.38 \%$, which is much greater than $60 \%$, showing that the degree of information loss after extracting the common factors is acceptable. That is to say they can accurately describe the financial performance of sample companies in the new energy automobile industry.

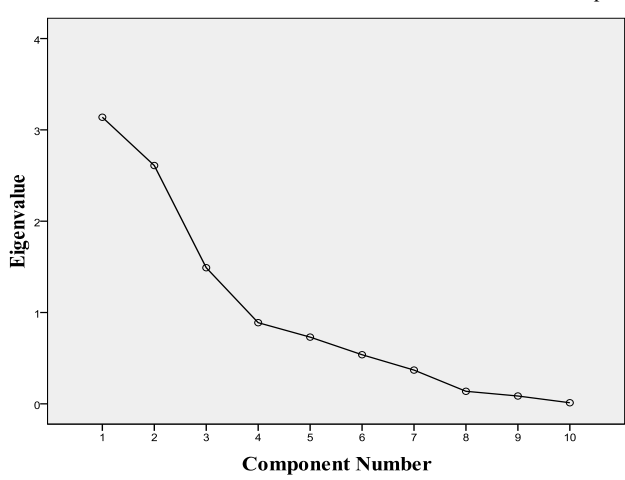

Fig.1 Scree Plot 
A scree plot displays the proportion of the total variation in a dataset that is explained by each of the components in a principle component analysis. Those components on the curve with greater slope are considered to represent the vast majority of the information of the original variables. The slope of the first three components in Fig. 1 is steeper and from the fourth one, the slope of the curve gradually decreases and eventually tends to be flat. Therefore, it can be suggested that the first three ones are sufficient to accurately summarise the financial performance of sample companies.

\section{Defining the factor variables}

In order to more clearly display the common factors represented by each variable, the maximum variance method is used and the load matrix is rotated, as shown in Table IV.

TABLE IV. ROTATED COMPONENT MATRIX

\begin{tabular}{|l|c|c|c|}
\hline & \multicolumn{3}{|c|}{ Component } \\
\cline { 2 - 4 } & $\mathbf{1}$ & $\mathbf{2}$ & $\mathbf{3}$ \\
\hline Current assets turnover & .948 & -.108 & .240 \\
Total assets turnover & .830 & .103 & -.286 \\
Receivables turnover & .689 & -.373 & .194 \\
Current ratio & -.677 & -.493 & .404 \\
Net profit margin & .593 & .493 & -.371 \\
Asset-liability ratio & & .884 & -.283 \\
Equity ratio & -.258 & .738 & .178 \\
Inventory turnover & .149 & .536 & .844 \\
Rate of return on total assets & .170 & & .739 \\
Cash ratio & -.152 & -.331 & \multicolumn{2}{|c|}{ Extraction Method: Principal Component Analysis. } \\
\hline
\end{tabular}

Rotation Method: Varimax with Kaiser Normalization.

The proportion of each variable shows the explanatory power and varying amount of the three principal components. The first common factor, F1, takes considerably large loads on current assets turnover A (94.8\%), total assets turnover A $(83.0 \%)$ and accounts receivable turnover rate (68.9\%), thus reflecting the company's operating ability; the second common factor, F2, has larger loads on assets-liabilities ratio (88.4\%) and equity ratio (73.8\%), reflecting the company's solvency; the third common factor, F3, accounts for larger loads on net profit margin (40.4\%) and return on total assets (ROA) A (84.4\%), reflecting the profitability of the company. The above three principal components exactly reflect the three representative indicators of sample companies.

D. Calculating the scores of the factors

TABLE V. COMPONENT SCORE COEFFICIENT MATRIX

\begin{tabular}{|c|c|c|c|}
\hline & \multicolumn{3}{|c|}{ Component } \\
\cline { 2 - 4 } & $\mathbf{1}$ & $\mathbf{2}$ & $\mathbf{3}$ \\
\hline current ratio & -.221 & -.163 & .104 \\
cash ratio & -.088 & -.055 & .401 \\
asset-liability ratio & -.028 & .356 & -.111 \\
equity ratio & -.108 & .313 & -.060 \\
receivables turnover & .278 & -.237 & -.258 \\
inventory turnover & .010 & .253 & .154 \\
current assets turnover & .327 & -.091 & -.038 \\
total assets turnover & .263 & .029 & .092 \\
rate of return on total assets & -.003 & .100 & .479 \\
net profit margin & .149 & .236 & .248 \\
\hline
\end{tabular}

Extraction Method: Principal Component Analysis. Component Scores
According to the score coefficient matrix of regression factor shown in table VI, the three factors are expressed as linear combinations of the 10 variables, and the formulas are as follows:

$$
\begin{aligned}
& F_{1}=-0.221 X_{1}-0.088 X_{2}-0.028 X_{3}-0.108 X_{4}+0.278 X_{5}+0.010 X_{6}+ \\
& 0.327 X_{7}+0.263 X_{8}-0.003 X_{9}+0.149 X_{10}
\end{aligned}
$$

$F_{2}=-0.163 X_{1}-0.055 X_{2}+0.356 X_{3}+0.313 X_{4}-0.237 X_{5}+0.253 X_{6}$ $0.091 X_{7}+0.029 X_{8}+0.100 X_{9}+0.236 X_{10}$

$$
\begin{gathered}
F_{3}=0.104 X_{1}+0.401 X_{2}-0.111 X_{3}-0.060 X_{4}-0.258 X_{5}+0.154 X_{6}- \\
0.038 X_{7}+0.092 X_{8}+0.479 X_{9}+0.248 X_{10}
\end{gathered}
$$

\section{E. Analyzing the results}

According to the above three formulas, the factor scores of sample companies are calculated respectively in terms of operating ability, solvency and profitability from 2015 to 2018. Then, the average scores of each factor are calculated with the formula below:

$$
Y=\left(0.30134 F_{1}+0.23715 F_{2}+0.18533 F_{3}\right) / 0.72383
$$

The calculation results are shown in Table VII.

TABLE VI. SUMMARY OF FACTOR SCORES

\begin{tabular}{|l|r|r|r|r|}
\hline Company Name & \multicolumn{1}{|c|}{$\mathbf{F}_{\mathbf{1}}$} & \multicolumn{1}{|c|}{$\mathbf{F}_{\mathbf{2}}$} & \multicolumn{1}{|c|}{$\mathbf{F}_{\mathbf{3}}$} & \multicolumn{1}{|c|}{$\mathbf{~}$} \\
\hline Ankai Bus & 0.210045 & 7.810332 & 2.675391 & 3.331369685 \\
Zhongtong Bus & 0.548282 & 5.055162 & 2.33574 & 2.482535317 \\
Yaxing Bus & -1.62225 & 8.590875 & 0.448292 & 2.254065036 \\
Jianghuai Car & 5.314518 & 2.271278 & -0.87422 & 2.732811956 \\
Jinlong Car & 0.354574 & 3.527462 & 1.178863 & 1.605160996 \\
Yutong Bus & 0.924985 & 2.473565 & 1.258012 & 1.517605446 \\
Futian Car & 1.747217 & 2.314451 & 0.440066 & 1.598352975 \\
Dongfeng Car & 1.625637 & 1.376543 & 0.086167 & 1.149836158 \\
Shangqi Group & 7.274609 & -1.30507 & -3.55993 & 1.689446482 \\
Jiangling Car & 4.923939 & -1.0326 & -2.07221 & 1.181016331 \\
BYD & 0.929898 & 1.076417 & -0.0492 & 0.727201529 \\
CHA & 2.662647 & 0.243856 & -1.26029 & 0.86570584 \\
Longmahuanwei & 0.728119 & 0.554123 & 0.457505 & 0.601814173 \\
Hualingxingma & 0.808473 & 1.002774 & -0.43638 & 0.553387541 \\
Zhongtai Car & 0.747084 & 0.331283 & 0.055896 & 0.433871426 \\
Beiqilangu & -0.95868 & 0.805594 & 0.466815 & -0.015647879 \\
Guangqi Group & 11.81985 & -6.52717 & -8.21724 & 0.678298065 \\
Changan Car & 15.59533 & -10.0448 & -12.3901 & 0.029186295 \\
Haima Car & 20.4196 & -15.1734 & -17.4781 & -0.945470452 \\
Changjiang Car & 31.60791 & -22.5204 & -26.4168 & -0.983412049 \\
Yiqi Car & 98.5728 & -80.988 & -89.3673 & -8.37877017 \\
\hline \multicolumn{4}{|r|}{}
\end{tabular}

In general, the results show an optimistic financial performance of Listed Companies in the new energy automobile industry, whereas development of each one tends to be unbalanced and unstable., 16 companies, accounting for $76.19 \%$ of the total 21 sample companies, score more than zero, indicating that their financial performance is sound. However, 8 of them score slightly greater than zero, showing their performance level is obviously lower than that of other industries, which indicates that the capital and human resource input into the industry is still insufficient. The top three listed companies are Ankai Bus, Zhongtong Bus and Yaxing Bus. Ankai Bus and Zhongtong Bus, which ranked first and second, have higher scores on solvency (7.810332 for the former and 5.055162 for the latter) and profitability (2.675391 and 2.33574 respectively) The third-ranked Yaxing Bus has the 
highest factor score of 8.590875 compared within the industry. Fig. 3, Fig. 4 and Fig. 5 are the scores of three main factors of Ankai Bus, Zhongtong Bus and Yaxing Bus from 2015 to 2018.

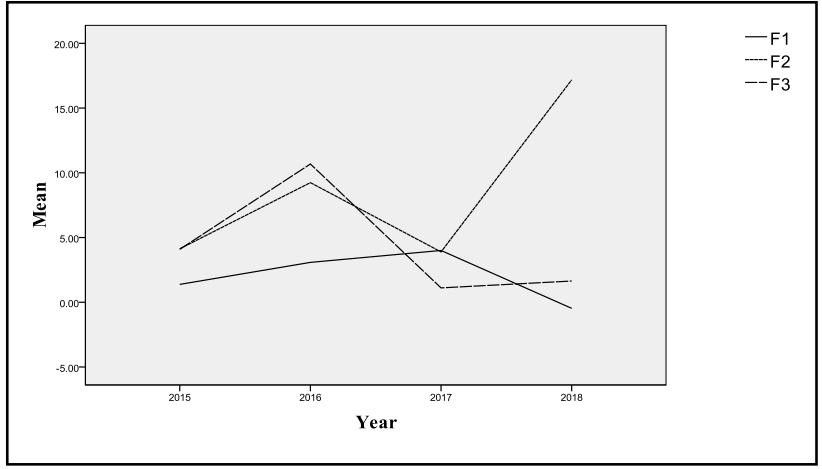

Fig.2 Ankai Bus

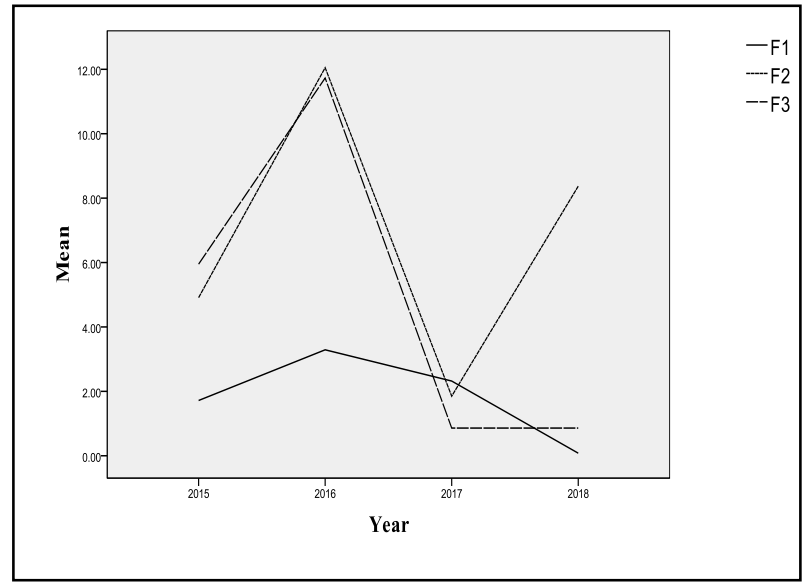

Fig.3 Zhongtong Bus

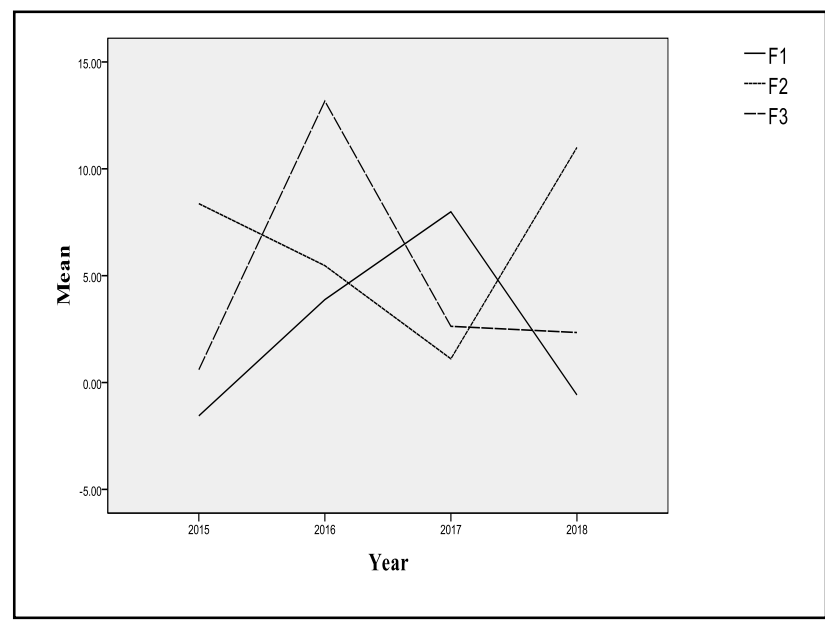

Fig.4 Yaxing Bus

From Fig. 2 to Fig. 4, it can be seen that the operating ability, solvency and profitability of the three listed companies are unstable from 2015 to 2018, and they differ greatly.
However, the solvency and profitability of the three companies are on the rise, though the operating ability is on the decline. Examining a single factor, the common factor F1 represents the company's operating ability, which weighs the highest among the three common factors, reaching $31.38 \%$. It can be identified as a key factor that affects the overall ranking Looking at the score value of the factor F1, it can be found that operating conditions in the period 2015-2018 are optimistic: 11 companies score greater than 1 on operating factor, and of the rest 10 , only two have negative scores, just slightly less than 0 , while others score between 0 and 1 .

TABLE VII. DESCRIPTIVE STATISTICS

\begin{tabular}{|l|r|r|r|c|r|}
\hline & \multicolumn{1}{|c|}{$\mathbf{~ N}$} & \multicolumn{1}{|c|}{ Minimum } & Maximum & Mean & Std.Deviation \\
\hline F1 & 21 & -.51647 & 4.04375 & .0000000 & 1.00000000 \\
F2 & 21 & -4.02837 & .70613 & .0000000 & 1.00000000 \\
F3 & 21 & -4.07025 & .49321 & .0000000 & 1.00000000 \\
Y & 21 & -4.02937 & .78558 & .0000000 & 1.00000000 \\
\hline
\end{tabular}

On the basis of Table VII, the results of descriptive statistics analysis are shown as Table VIII. It can be seen that under the premise of standardization, the gap between the minimum value and the maximum value is still large, which also shows that the financial development of new energy automobile listed companies is unbalanced and unstable.

\section{CONCLUSION AND SUGGESTION}

Based on the results of the above factor analysis, the paper puts forward the corresponding countermeasures and suggestions for the development of Listed Companies in the new energy automobile industry.

From the perspective of companies:

Listed Companies should focus on balanced and stable development. The above analysis shows that the companies with the highest performance scores do not perform well in three aspects at the same time, which indicates that most of the listed companies have some problems in different aspects and have not achieved a real balanced development in an all-round way. As far as a single company is concerned, it should improve its financial management system according to its own shortcomings, and build a suitable financial and operational management mechanism, so as to accelerate its development process.[6]

From the perspective of the government:

The government should invest more in the new energy automobile industry in order to improve the financial performance of listed companies. The performance scores of the sample companies generally remain at a low level. New energy automobiles do not have patents and technological advantages, and there is little differentiation for them to charge a premium price.[7] Therefore, listed companies need to increase their R\&D investment, which needs strong support from the government. In 2016, the NPC and CPPCC set the prospection that by 2020, China will become an innovative country with powerful human resources. An innovative country requires that $R \& D$ investment accounts for more than $2.5 \%$ of 
GDP; that the contribution rate of scientific and technological progress is more than 70\%; and that dependence rate of foreign technology is less than $30 \%$. Although the government supports the development of new energy automobile industry, its support is far from enough compared with western developed countries. Besides, the new energy automobile companies should make full use of the national policy, increase R\&D investment, and improve the level of scientific and technological innovation.[8] Only by following the guidance of the national policy, can they have better development prospects and greater social contribution, and thus improve the financial performance and increase their competences.

\section{REFERENCES}

[1] B.Y. Dong, "Development Status, Problems and Countermeasures of New Energy Vehicles in China,” Journal of Enterprise Economics, vol. 34(03), pp. 145-148, 2015. (In Chinese)

[2] Y.Q. Wang, "Historical Changes in China's Environmental Protection Policy -- Speech at the Fifth Session of the Environmental and
Economic Policy Research Center of the Ministry of Ecology and Environment 'China's Environmental Strategy and Policy Lecture' on April 27,” Environment and sustainable development, vol. 43(04), pp. 5-9, 2018. (In Chinese)

[3] J.H. Wang, R.T. Li, "Construction and Application of Performance Evaluation System for New Energy Listed Companies,” Friends of Accounting, vol. (22), pp. 78-82, 2018. (In Chinese).

[4] H.Y. Yong, S.L. Li, "Using Principal Component Analysis to Evaluate the Performance of Listed Companies," Scientific Management Research, vol. (04), pp. 66-69, 2004. (In Chinese).

[5] J.P. Wang, N. Wang, "Financial Analysis and Evaluation of Listed Energy Companies in China-based on Principal Component Analysis," Friends of Accounting, vol. 11, pp. 60-66, 2016. (In Chinese)

[6] J.X. He, Z.Y. Yang, X. Yang and Y. Qing, "Research Status and Development Trend of New Energy Vehicle,” Science and Technology Innovation, vol. (12), pp. 177-178, 2019. (In Chinese)

[7] J. Jin, M. McKelvey, "Building a sectoral innovation system for new energy vehicles in Hangzhou, China: Insights from evolutionary economics and strategic niche management," Journal of Cleaner Production, pp. 224, 2019.

[8] H. Lin, Y.H. Ma, "The Reform Path of Ecological Compensation System,” Chinese land, vol. (05), pp. 26-28, 2019. (In Chinese) 